\title{
Derechos humanos y estándares laborales en las organizaciones, de cara al posconflicto en Colombia
}

\author{
Human rights and labor standards in organizations, facing a \\ post-conflict of Colombia
}

Andrés Felipe Ochoa-Cubillos ${ }^{1}$, Edgar Alonso Vanegas-Carvajal ${ }^{2} \&$ Sandra Lucía Arizabaleta-Domínguez $^{3}$

\begin{abstract}
Resumen
Este trabajo busca, a partir de un análisis crítico hermenéutico, reivindicar la idea de dignidad humana como parte de la ética y responsabilidad empresarial en un marco de posconflicto y/o construcción de paz en Colombia. Mediante la revisión documental de artículos, libros, informes de investigación e informes institucionales, relacionados con diferentes conflictos nacionales e internacionales, se establecen los roles que las organizaciones públicas, privadas y del tercer sector, deben desempeñar para garantizar la construcción de paz; y así, proponer mínimos éticos relacionados con el respeto y refrendación de los DD.HH y los estándares laborales.
\end{abstract}

Palabras clave: Dignidad humana; ética empresarial; derechos humanos; estándares laborales; posconflicto; construcción de paz

\begin{abstract}
From a critical hermeneutic analysis, this article aims at reclaiming the idea of human dignity as part of corporate ethics and responsibility in the post-conflict and/or peace-building context in Colombia. Through the documentary review of articles, books, research reports and institutional reports, related to different national and international conflicts, the roles that public, private and third sector organizations must perform to guarantee peace-building are established. Based on that, some ethical minimums related to the respect and endorsement of human rights and labor standards are proposed.
\end{abstract}

Keywords: Human dignity; business ethics; human rights; labor standards; post-conflict; peace-building

Tipología: Artículo de investigación científica y tecnológica

Recibido: $29 / 03 / 2016$

Evaluado: $14 / 08 / 2016$

Aceptado: 13/10/2016

Disponible en línea: 01/03/2017

Como citar este artículo: Ochoa-Cubillos, A.F., Vanegas-Carvajal, E.A. \& Arizabaleta-Domínguez, S.L. (2017). Derechos humanos y estándares laborales en las organizaciones, de cara al posconflicto en Colombia. Jangwa Pana, 16 (1), 38 - 53. Doi: http://dx.doi. org/10.21676/16574923.1955

\footnotetext{
1. Magister en Administración. Docente investigador. Fundación Universitaria Católica -Lumen Gentium. Colombia. Correo electrónico: afochoa@ unicatolica.edu.co. ORCID ID: 0000-0002-1069-0119

2. Especialista en Pedagogía y Docencia Universitaria. Doctorando en Filosofía. Docente Universidad Pontificia Bolivariana. Colombia. Correo electrónico: edgar.vanegas@upb.edu.co. ORCID ID: 0000-0001-6124-3944

3. Magister en educación superior. Docente investigador Fundación Universitaria Católica-Lumen Gentium. Colombia. Correo electrónico: sarizabaleta@unicatolica.edu.co. ORCID ID: 0000-0001-6255-009X
} 


\section{Introducción}

$\mathrm{E}$ ste estudio busca reivindicar la idea de dignidad humana como condición de la ética empresarial en un contexto de construcción de paz o peacebulding, que facilite la interpretación de los Derechos Humanos (DD.HH) en el sector empresarial colombiano y propenda por la determinación de principios que permitan a las organizaciones (públicas, privadas o del tercer sector) garantizar el ideal de dignidad humana como fundamento de la ética empresarial, a partir de la toma de decisiones éticas y responsables, y así contribuir a la regulación de un escenario afectado por el conflicto y la violencia, y facilitar la transición hacia un escenario de posconflicto o construcción de paz, estable, duradero y de no repetición.

El concepto peacebulding surge del discurso posbélico para referirse a "construcción de la paz posbélica" o de posconflicto, diferenciándola de otras misiones de paz, como "diplomacia preventiva, mantenimiento de la paz e imposición de la paz" (Grasa y Mateos, 2014, p. 33 y 34). Miranda, Palou, Llorente, Rivas, Prieto y Navarrete (2012) hablan de "Peacemaking" para referirse al cese al fuego, tratados de paz y acuerdos sobre Desarme, Desmovilización y Reintegración(DDR). Construcción de paz: se refiere, en el contexto de un acuerdo para acabar la violencia armada, a todos los esfuerzos para identificar y apoyar estructuras que propendan por consolidar la paz y mejorar la confianza y bienestar de las personas.

Dentro de los diversos actores que participan en un proceso de construcción de paz, se destaca el sector empresarial (Grasa y Mateos, 2014). Tanto las guerras como los conflictos (nacionales y/o regionales) se presentan dentro de un contexto complejo, asimétrico y disímil, donde cada grupo en contienda busca imponer su ideología, modelo socio-económico y paradigma ético-político; y lo hace generalmente apoyado en las armas, desestabilizando el tejido social y causando daños e impactos negativos en personas, empresas, instituciones y ecosistemas (Izaguirre y Aguiar,
1998; Rojas Aravena y Goucha, 2001; Rubio, Ramírez, Fandiño, Suárez, y Mesías, 2004).

La construcción de la paz, va más allá de "hacer las paces", "mantener la paz" o "imponer una determinada paz"; implica desarme y destrucción de armas, desmovilización y reinserción, reintegración de excombatientes, repatriación de refugiados, reformas a la justicia, liberación de secuestrados, participación política de los excombatientes, formación de agentes defensores de derechos humanos, derechos humanos con enfoque diferencial, procesos educativos $y$ formación de facilitadores, capacitación a personal de la fuerza pública, inclusión social y laboral a desmovilizados, verdad y reparación a víctimas, entre otros elementos imprescindibles en los acuerdos para terminar la violencia armada y que se deben implementar en un nuevo escenario de posconflicto, no menos importante que los acuerdos (Miranda et al., 2012; Vargas Valdez, 2010).

Estos elementos de resolución del conflicto se articulan con el principio de dignidad humana, como condición del discurso de los DD.HH en las empresas. Según Navanethem Pilay (2009), "Los derechos humanos son normas básicas destinadas a garantizar la dignidad e igualdad para todos" (p. 2), es decir, el reconocimiento del "otro" y de lo "otro", que es diferente por situarse en otra orilla ideológicopolítica, pero que constituye un interlocutor válido para dialogar entre iguales. Así, los principios de igualdad y de reconocimiento, configuran las bases filosóficas para postular unos mínimos de moralidad irrenunciables y exigibles, que permitan dialogar, llegar a acuerdos y posteriormente convivir, en niveles de civilidad conforme a nuestra condición humana, con el fin de establecer una sociedad más justa donde puedan interactuar de manera cordial los distintos grupos sociales.

Los análisis y reflexiones presentados en este trabajo surgen de un análisis crítico hermenéutico de artículos, libros, informes de investigación e informes institucionales, revisados en torno a eventos significativos, ocurridos en diferentes escenarios nacionales e internacionales. En este análisis, identificamos el rol que las organizaciones 
públicas, privadas $\mathrm{y}$ del tercer sector han desempeñado en el conflicto y el que deberán desempeñar en el posconflicto o construcción de paz; un rol que permita proponer mínimos éticos relacionados con el respecto y refrendación de los DD.HH y estándares laborales que estos actores deben garantizar como aporte a un proceso de construcción de paz.

Para el análisis se identificaron documentos técnicos, científicos y académicos, en Scopus, Science Direct, Dialnet, entre otras bases de datos, revistas científicas especializadas en la temática de estudio e informes de entidades de carácter nacional e internacional (OIT, Naciones Unidas, CCB, ONG's), para un periodo de 20 años (19952015). Se revisaron 189 productos, de los cuales se tomaron 51 como referencia para para este estudio.

\section{Resultados y Discusión}

\section{Construcción de una sociedad éticamente digna y más justa}

Cortina (2002) plantea que las sociedades modernas se componen de un conjunto de "valores como mínimos éticos irrenunciables de justicia desde los que deben ir respondiendo conjuntamente a retos comunes. La ética mínima tendrá entonces aquellos mínimos de justicia por debajo de los cuales una sociedad no puede caer sin perder su moralidad" (p. 46 y 50).

Esta plataforma ético-política se plantea dentro de las sociedades occidentales del siglo XXI, caracterizadas por ser democráticas, diversas y multiculturales, y es esta plataforma, la base para crear una convivencia dentro del campo empresarial, basada en la idea de dignidad, reconocimiento del otro, respeto a las identidades y garantía a los DDHH.

Las organizaciones, como representaciones a escala de la sociedad, están constituidas por personas "capital humano" -, con derechos y deberes; que tienen su propia historia y cultura, comparten un mismo territorio y valores. Estas personas, aunque de forma distinta, han vivido un mismo conflicto armado, como víctimas o victimarios, y buscan en distinta medida ser integrados a la sociedad. Al estar constituida la empresa por personas de distintas etnias, tejido axiológico, culturas, ideologías y concepciones de "vida buena", es necesario establecer unos estándares o principios mínimos, desde los que cada persona se involucre directamente con el cumplimiento de los objetivos empresariales y sociales, como punto de partida para la configuración de una determinada ética empresarial acorde a los desafíos de un escenario de posconflicto.

Dentro de las recomendaciones que proponen la Cámara de Comercio de Bogotá y la Fundación Ideas para la Paz (CCB y FIP, 2015) en materia de apoyo a Personas en Procesos de Reintegración (PPR), destaca la importancia que tiene la cultura organizacional como factor determinante en el proceso de reintegración de personas desmovilizadas que lleguen a la empresa:

La experiencia muestra que una cultura
organizacional sólida (con valores, costumbres,
normas y expectativas basadas en el respeto, la
empatía y la claridad) puede facilitar el buen
desarrollo de los procesos de vinculación
laboral de PPR y, por lo tanto, de la iniciativa
en general. (CCB y FIP, 2015, p. 33)

En un escenario de posconflicto en Colombia, como sustenta Brenkert (2010), es necesario que las organizaciones, especialmente la empresa privada, como actores del conflicto (directo o indirecto), trasciendan el paradigma de la maximización del beneficio empresarial y desarrollen un trabajo significativo desde la revisión de su ética empresarial. Según Goodpaster (1991), las organizaciones deben propender por la restauración de la dignidad de los empleados y de sus actores de influencia (stakeholders).

Son las empresas las llamadas a instar el desarrollo de regulaciones/políticas gubernamentales que propendan por fortalecer el comportamiento ético en ellas y no lo contrario, que éstas se conviertan en promotoras de regulaciones insulsas y amañadas, 
dirigidas a maximizar el beneficio económico, en detrimento de la dignidad de los stakeholders.

Aun cuando se parte del paradigma de la maximización del beneficio, el cual se reconoce como el fundamento económico natural de las empresas desde los postulados de David Ricardo (1815) y Adam Smith (1776), los planteamientos resultantes de este estudio no se conciben en perjuicio de la naturaleza de las empresas como ente generador de utilidades; por el contrario, se formulan como fundamento normalizador de las relaciones de las organizaciones, en especial del sector privado, con sus actores de influencia y su entorno de operación, lo que teóricamente tiende a maximizar los beneficios económicos (Crespo, 2003).

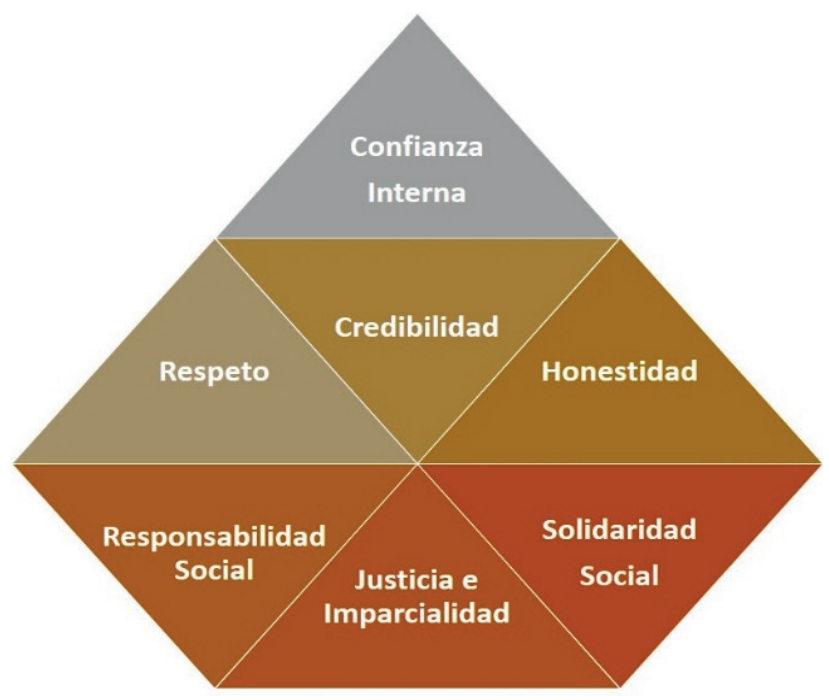

Figura 1. Valores mínimos de la ética empresarial Fuente: (Brito, 2007) / Elaboración: propia de los autores

Para la normalización de estas relaciones, se propone que las organizaciones incorporen a sus rutinas de gestión una serie de variables intangibles mínimas (valores) que la sociedad espera sean respetadas por cualquier actor que en ella interactúe (Figura 1), y que permitirían un "equilibrio entre el rendimiento económico y el rendimiento social" (Brito, 2007; Llano y Llano, 2004).

No obstante, el respeto a la dignidad humana y las libertades fundamentales, personales, sociales $\mathrm{y}$ organizacionales, no han sido la constante en el contexto colombiano, social y/o empresarial. La transgresión y violación sistemática de los DD.HH a personas, grupos sociales, empresas, agremiaciones y trabajadores de organizaciones públicas, privadas y del tercer sector (Molina, 2015), ha sido una constante en los últimos sesenta años en Colombia (Bello, 2003; Naciones Unidas, 2015; Rettberg, 2010).

Las organizaciones privadas, públicas o sociales llamadas a contribuir con la generación de condiciones que posibiliten el desarrollo humano sostenible, han sido afectadas de forma negativa por el conflicto armado interno. Recíprocamente, éstas han vulnerado derechos fundamentales $\mathrm{y}$ laborales de los trabajadores; es decir, han jugado el doble rol de víctimas y victimarios.

Las empresas que operan o han operado en Colombia se han visto expuestas a extorsión, secuestro, problemas de seguridad, pérdida de reputación e incluso atentados contra sus instalaciones, sus empleados y/o sus contratistas (Alvarez y Rettberg, 2008; Gómez, 2015; Guáqueta, 2006; Rettberg, 2003, 2008); otras tantas, están siendo investigadas por transgredir de manera sistemática en la dignidad humana a sus empleados y a la sociedad misma, al incurrir en prácticas como: corrupción, pagos injustos y a destiempo, no pago de prestaciones sociales, despidos injustificados, restricciones a las libertades sindicales, dineros y donaciones de dudosa procedencia, vínculos con bandas delincuenciales, entre otros (Bello, 2003; Iglesias, 2010; Rettberg, 2003, 2008).

En el contexto colombiano, la ética empresarial se enfrenta a dos fenómenos contradictorios que la confirman como esencia de las organizaciones y de su relación con la sociedad, pero la desvirtúan como fundamento delimitante de su actuar (decisiones). Por un lado, está la proliferación de empresas que incursionan y promulgan desarrollar sus actividades en el marco de la ética empresarial y la Responsabilidad Social Corporativa (RSC), confirmando la relevancia que la ética empresarial ha adquirido para las organizaciones. Del otro lado, están los continuos y casi cotidianos sucesos reprochables de organizaciones privadas, públicas 
y del tercer sector, por ejemplo, la corrupción (Tindall, 2014; Tsalikis, Seaton y Shepherd, 2014), que ponen en entredicho la ética empresarial y principios de RSC de estas organizaciones.

Esta ambigüedad mostrada por las empresas en el contexto colombiano permite concluir que la responsabilidad social, de ser una dimensión de la ética, se ha convertido en tan solo una herramienta que las empresas utilizan para recuperar su legitimidad; donde la asunción de responsabilidad, justicia, responsividad y empatía, propuestas por Muñoz-Martín (2013), no estructuran la ética empresarial, lo que hace de esta un elemento difuso en las organizaciones, un elemento de materialización de una ética inexistente pero que las organizaciones cobran como parte de sí, ya sea mediante la reducción de impuestos (exención), del marketing o alguna otra maniobra administrativa.

\section{Dignidad humana, fundamento de los derechos humanos en la empresa}

La corrupción representa un desafío para las empresas que operan en zonas de conflicto armado, ya sea por sobornos, cobro de comisiones, extorsiones, dineros por protección, pagos de facilitación, fraude, lavados de dinero, tráfico de influencias y/o contribuciones políticas o de caridad, lo que repercute en la intensificación del conflicto.

Las empresas pueden proporcionar
inadvertidamente medios financieros o
materiales que faciliten el conflicto armado,
causando para sí mismos [mismas] riesgos
de credibilidad, legales, operacionales y
financieros. Estos pueden suceder a través
de relaciones y transacciones comerciales
con partes del conflicto, la administración
inadecuada de la cadena de suministros o,
por medio de pagos y/o extorsiones a grupos
armados. (UNITED NATIONS GLOBAL
COMPACT, 2010, p. 14)

Un caso paradigmático, a escala nacional e internacional, por las decisiones tomadas en el contexto de conflicto armado en Colombia y por las implicaciones para las empresas que operan en este país, es el caso Chiquita Brands International. Esta empresa, en la década del 90, según su justificación, toma la decisión de pagar a los grupos paramilitares del Urabá antioqueño y Córdoba, a cambio de la seguridad de sus empleados.

En un análisis, la British Broadcasting Corporation (BBC Mundo) presenta un reportaje donde informa:

El caso saca a relucir un fenómeno común para las empresas extranjeras en Colombia, el cual es un secreto a voces. El analista político colombiano Alfredo Rangel dijo a la BBC que muchas empresas son víctimas de las extorsiones de la guerrilla y los paramilitares, en especial las exportadoras. "Al extorsionarlas estos grupos obtienen recursos que les permiten acceder al tráfico internacional ilegal de armas". El problema no se limita, sin embargo, a las empresas extranjeras. Las nacionales son igualmente blanco de los grupos irregulares. Todo este proceso se hace a espaldas del gobierno, pues en Colombia dichos pagos son ilegales. En su defensa, Chiquita Brands aseguró que los grupos irregulares amenazaron a sus trabajadores y son conscientes de que están considerados como terroristas. (BBC Mundo, 2004, p. 12-05)

El caso es solo una muestra de la situación de las empresas que operan en Colombia. Por un lado, la decisión de pagar extorsiones a grupos considerados terroristas representa un comportamiento ético cuestionable que puede configurar un acto ilegal en Colombia y Estados Unidos, y por otro lado, las decisiones emprendidas lograron ser legitimadas por las directivas de Chiquita y por la mayoría de empleados, incluso por diferentes grupos sociales que justifican las acciones de esta compañía, argumentando proteger la dignidad y los derechos fundamentales de los empleados para no ser atacados durante su estancia en Colombia. Bunse y Colburn (2009) describen que "la fiscalía y la Bananera acuerdan que esta última debe implementar un programa de ética con el fin de garantizar la legalidad de sus prácticas dentro de su empresa" (p. 176).

Surge entonces un cuestionamiento: ¿la buena fe y la preocupación por la seguridad de los empleados, 
entendida como garantía a la dignidad humana, justifica el pago a grupos ilegales en Colombia? Se ha enseñado, dentro de una ética deontológica de corte kantiano, que el fin, por muy noble que parezca, nunca justifica los medios, donde la persona en su más profunda acepción representa el centro, el culmen y el fin último de cualquier acción emprendida. Pareciera entonces que la entrega de dinero a grupos denominados "terroristas" se torna una práctica corrupta, ilegítima e ilegal, a todas luces, incluso en medio del conflicto, ya que esto proporciona medios a grupos violentos para financiar sus actos delictivos contra de otras organizaciones y personas.

El embajador de Estados Unidos en Colombia, William Brownfield, concluyó: "no es una justificación aceptable", al referirse a la justificación de Chiquita Brands, de pagar a paramilitares a cambio de seguridad y protección de sus empleados (Bunse y Colburn, 2009).

Este caso lleva a un interrogante necesario: ¿se puede hablar de dignidad en las empresas? La pregunta se relaciona con el interrogante propuesto por Taylor (1993): ¿tienen las culturas igual dignidad? ¿Se podría decir que las empresas tiene conciencia?, o incluso ¿la categoría de persona puede emigrar y dar sentido a las empresas?

En Colombia, estos planteamientos han sido ampliamente debatidos. Por ejemplo, se ha discutido si las instituciones de salud pueden objetar conciencia cuando la vida está en juego, como en los casos de despenalización del aborto y la eutanasia. Esto lleva a considerar si se puede definir/dimensionar la ética de una organización y en caso positivo ¿cuáles serían sus parámetros? No obstante, así como la dignidad humana constituye la condición de posibilidad para el desarrollo de los DD.HH, la dignidad organizacional constituye la base y el fundamento de un comportamiento ético en las organizaciones, como garante de los DD.HH.

En las organizaciones se produce un tejido axiológico, producto de identidades individuales, interacciones entre empleados, relación con el entorno, ámbito cultural, normas y prácticas de la organización, y lineamientos estratégicos (misión-visión-objetivos). Así, aparece la cultura organizacional como el entramado de pautas de pensamiento y conductas, reguladas por normas, con el fin de dirigir y organizar las distintas prácticas, adaptando el entorno laboral a las necesidades y fines de la organización, legitimadas por valores corporativos que la identifican.

Las organizaciones han replanteado la gestión a partir de la incorporación de valores y principios, articulados mediante bases axiológicas como: calidad, justicia distributiva, solidaridad, autonomía, reconocimiento, transparencia e imagen corporativa. Esto repercute necesariamente en patrones de conducta que se ven reflejados en los resultados productivos de la organización, bajo estándares de calidad, efectividad, eficiencia y responsabilidad social, que configuran la ética empresarial (Cortina, 2006) o ética organizacional (Villafañe, 2003).

Los valores compartidos surgen de la cultura organizacional, luego, se convierten en principios morales que orientan las decisiones y acciones dentro de la organización, y se vuelven compatibles con los valores sociales y culturales del entorno. La ética social y organizacional sustenta que las decisiones éticas y las acciones de responsabilidad social, dentro del campo laboral de una organización, no son de carácter personal sino organizacional, ya que repercuten en toda la organización, y están encaminadas a la consecución de fines y propósitos de la organización. Por lo tanto, la cultura organizacional representa la conciencia colectiva que comparten los miembros de una organización como resultado de un conjunto de prácticas, discursos, valores, principios, historia, signos y símbolos, enfocados a la consecución de metas y fines planteados en la misión-visión de la organización.

Dentro de la ética organizacional, las instituciones amplían su radio de acción organizacional. Inicia con el empleado y progresivamente incluye a la familia como agente principal en los procesos 
intra-organizacionales, reduciendo la brecha entre el proyecto de vida personal y el institucional, con miras a implementar niveles de eficacia, eficiencia y efectividad.

Las organizaciones, igual que culturas y personas, nacen, crecen, a veces se reproducen (o se transforman) y mueren. Esto permite asociar la dignidad constitutiva a las empresas, debido a que son conformadas por personas que cobran su propia dignidad. No obstante, hablar de dignidad humana y de dignidad empresarial resulta complejo y abstracto: su sentido es polisémico; y sea en términos de Kant, Habermas, Spamann, Rawls u otro, la dignidad siempre tiene como fin teleológico el valor intrínseco de la persona, por el solo hecho de ser; por consiguiente, no puede ser utilizada como instrumento, sino que es el fin de toda conducta. Hablar de dignidad es también hablar de ética de los derechos de las personas; derechos que toda empresa debe proteger, garantizar y restituir, cuando estos sean vulnerados.

Esta plataforma ético-política constituye la posibilidad de buenas prácticas organizacionales y de trabajo decente: inclusivas, iguales, interculturales, justas y dialógicas, donde todos sean reconocidos (valorados) desde sus propias identidades y capacidades (Hernández, 2006).
...Como dijo el Papa Benedicto XVI, el trabajo es fundamental para la realización personal y el progreso de la sociedad, y por esto es preciso que siempre se le organice y desarrolle con pleno respeto a la dignidad humana y al servicio del bien común. El trabajo está vinculado con la paz. La comunidad en la que la gente tiene trabajo es una comunidad en paz. En el concepto de trabajo decente hay un reconocimiento de que no es posible tener sociedades estables basadas en la desigualdad social, así como no es posible tener desarrollo social basado en economías inestables. (Somavía, 2014, p. 49)

Estas son las empresas deseables dentro de cualquier sociedad; especialmente en países en conflicto armado, donde la vulneración sistemática a los derechos fundamentales es reiterativa $\mathrm{y}$ persistente.

Organismos multilaterales como la NU, OCDE y la OIT, han promovido la implementación de estándares, principios y códigos internacionales, orientados a la protección de la dignidad, los derechos fundamentales, el medio ambiente, la lucha contra la corrupción, y en pro de la transparencia y los derechos de los trabajadores, en regiones en conflicto armado, como por ejemplo, los principios del pacto global (Figura 2).

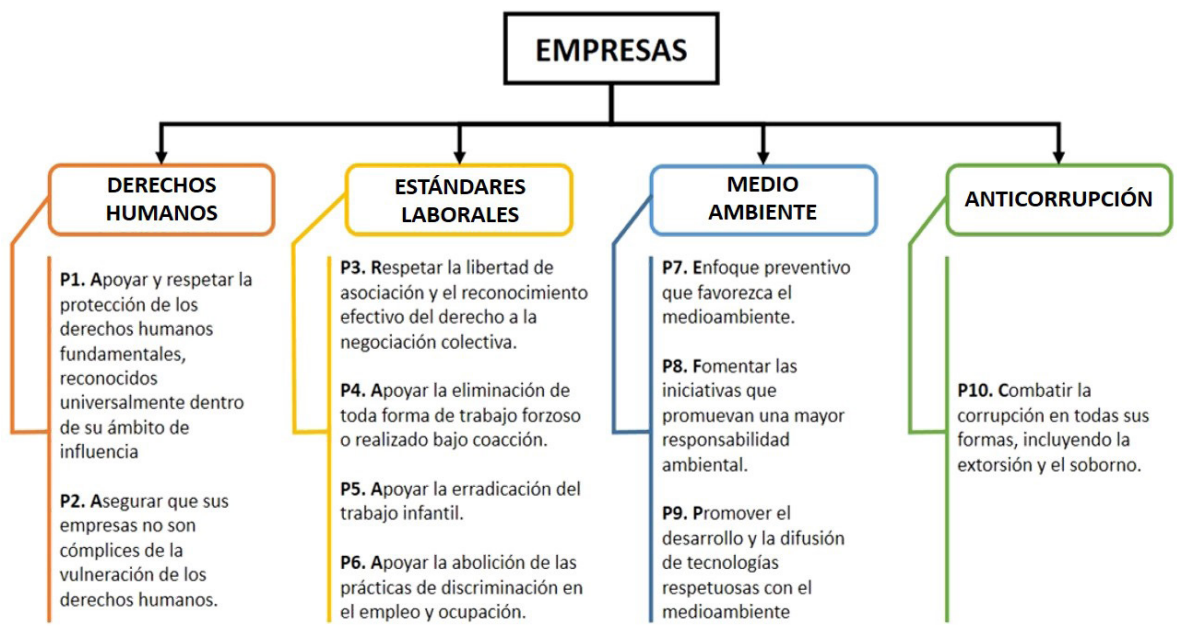

Figura 2. Principios del Pacto Global para las Buenas Prácticas Éticas en las Empresas Fuente: UEC y Red Pacto Global $(2015$, p. 3) / Elaboración: Propia de los autores 
Los principios del Pacto Global están encaminados a orientar las buenas prácticas éticas y de Responsabilidad Social dentro de las Empresas, a partir del respecto por los DD-HH, los estándares laborales, el medio ambiente y la lucha por la corrupción.

Este estudio se centra en los primeros seis principios relacionados con los DD.HH y Estándares Laborales (Universidad Externado de Colombia y Red Pacto Global Colombia, 2015).

La OIT, mediante el Programa de trabajo decente para los trabajadores domésticos - trabajo digno, plantea la necesidad del reconocimiento de las libertades esenciales de los trabajadores dentro de las empresas, principalmente la inclusión y no discriminación, libertad sindical, eliminación de cualquier tipo de trabajo forzado y trabajo infantil, o cualquier forma laboral que vulnere la dignidad humana (OIT, 1999).

El Colombia, el Libro Blanco sobre empresas y derechos humanos en Colombia (Fundación Ideas para la Paz y Embajada Británica en Bogotá, 2012), constituye la hoja de ruta en la implementación de estándares nacionales e internacionales, en la medida que estos puedan aplicarse a las empresas colombianas en circunstancias de conflicto armado, que incentiven y promuevan las buenas prácticas empresariales, basados en la responsabilidad social y propicien negocios prósperos y estables. Este texto plantea como uno de los pilares "la necesidad de un mayor acceso a las víctimas a un remedio efectivo" (p. 6). La Fundación ideas para la paz, en cooperación con otros organismos (nacionales e internacionales), ha proporcionado recursos bibliográficos y científicos, encaminados a definir la labor de las empresas en la construcción de paz en un escenario de pos-conflicto en Colombia.

Las empresas, públicas o privadas, deben garantizar los derechos fundamentales de los trabajadores (Figura 3) y su dignidad humana per se, además deben restituirla en caso de ser vulnerada. La OIT considera cuatro conductas empresariales que vulneran directamente la dignidad humana y dañan profundamente la esencia de la persona: trabajo forzado, discriminación, trabajo infantil y prácticas de exclusión, desigualdad e injusticia

\begin{tabular}{|c|c|}
\hline \multirow{8}{*}{$\begin{array}{l}\text { DERECHOS } \\
\text { FUNDAMENTALES DE } \\
\text { LOS TRABAJADORES }\end{array}$} & - Libre elección del oficio \\
\hline & - Agremiación sindical \\
\hline & - Huelga \\
\hline & - Información y participación dentro de la empresa \\
\hline & - Formación y desarrollo de competencias y capacidades \\
\hline & - No ser discriminados \\
\hline & - Remuneración Justa \\
\hline & - Libertad de pensamiento \\
\hline
\end{tabular}

Figura 3. Derechos Fundamentales de los Trabajadores

Fuente/Elaboración: propia de los autores

La dignidad y la garantía de los derechos fundamentales no se dan a cualquier precio; requieren condiciones de contexto, voluntad empresarial, políticas públicas y un sistema jurídico, encaminados a mejorar las garantías laborales, salariales y a garantizar el ejercicio de libertades, que tradicionalmente han sido restringidas, como: derecho a la protesta y libre asociación. Aunque la dignidad es una y la misma en toda persona, cada escuela ética la ha definido a su manera. Para este caso y dada la particularidad del campo empresarial, se ha seguido la tradición Kantiana y Spaemanniana, al conceptualizarla como el reconocimiento de "alguien" y no de "algo", digno de respeto, con valor intrínseco e inalienable, que no tiene precio, que no se puede comprar o vender, que no se puede cambiar, enajenar o rechazar, ni siquiera por el mismo propietario. 
...se entenderá el concepto de dignidad humana, a partir de cinco elementos constitutivos: primero, la no instrumentalización; segundo, la vida digna; tercero, la libertad de conciencia; cuarto, la solidaridad; y quinto la autoestima. En este mismo sentido, la antropología cristiana reconoce y entiende la dignidad humana en términos personalistas como "imago Dei" y, por tanto, no puede ser reducido a una partícula del cosmos ni a un elemento anónimo y aislado de la sociedad. Sino que por el contrario implica un elemento de grandeza y de misterio absoluto en el otro, que exige un respeto total, que impide la condena radical y prohíbe la manipulación del otro. (González, 1987, p. 16)

La OIT, retomando la Declaración de Filadelfia (1947), afirma que:

Todos los seres humanos, sin distinción de raza, credo o sexo, tienen derecho a perseguir su bienestar material y su desarrollo espiritual en condiciones de libertad y dignidad, de seguridad económica y en igualdad de oportunidades. (OIT, 1999, p. 78)

En la Declaración Universal de los Derechos Humanos - DUDH (Art 23):

Toda persona tiene derecho al trabajo, a la libre elección de su trabajo, a condiciones equitativas y satisfactorias de trabajo y a la protección contra el desempleo, sin discriminación alguna, a igual salario por trabajo igual, a una remuneración equitativa y satisfactoria, que le asegure, así como a su familia, una existencia conforme a la dignidad humana y que será completada, en caso necesario, por cualesquiera otros medios de protección social, a fundar sindicatos y a sindicarse para la defensa de sus intereses. (Asamblea General de las Naciones Unidas, 1948, p. 4)

El discurso sobre la dignidad humana y los DD.HH es quizás uno de los más preponderantes en el siglo XXI, no solo como elemento legitimador de los Estados Sociales de Derecho, que han optado por una estructura democrática, sino también por ser, quizás, el modelo socio-político más cercano o acorde a las sociedades multiculturales, plurales, laicas y diversas, fundadas en los principios de libertad individual y autonomía. En efecto, la dignidad humana constituye uno de esos principios que fundamenta la Constitución colombiana, al definir a Colombia como "un Estado Social de Derecho $[\ldots]$ fundada fundado en el respecto a la dignidad humana [...]" (Art. 1, Constitución Política de Colombia - CP).

En un escenario de posconflicto, donde las libertades fundamentales no han sido totalmente reconocidas, ya que persisten daños personales, sociales y estructurales, la dignidad humana a través del trabajo digno debe ser la principal tarea para garantizar una paz estable y duradera, ya que el trabajo está directamente relacionado con la paz y la justicia social. La OIT plantea que en las actuales circunstancias "necesitamos instituciones, políticas y liderazgo a nivel mundial que defiendan y encarnen, la dignidad humana y los DD.HH" (OIT, 1999, p. 27).

\section{La empresa y la construcción de paz estable y duradera en el posconflicto}

La construcción de paz, en los términos de Grasa (2011), es una categoría polisémica, que está referida a un conjunto de actuaciones en la fase posbélica, encaminadas a evitar nuevas confrontaciones armadas, donde intervienen actores públicos y privados, nacionales, regionales y locales, en tiempos no menores a 15 años.

En este marco, la contribución del sector productivo empresarial, debe movilizarse en torno a la consecución de la paz. La contribución del sector empresarial a la construcción de paz en el posconflicto de países como El Salvador, Guatemala, Sudáfrica, Nigeria, Kosovo (1999), Irlanda del Norte (1998) y Eritrea (2002 y 2006), constituye un referente importante para el caso colombiano (Collier, Hoeffler y Söderbom, 2008; Idahosa, 2002; Idemudia, 2010, 2014; Katsos y Forrer, 2014; Kolk y Lenfant, 2013; Rettberg, 2007). Es innegable el rol determinante que juega el sector empresarial en una paz negociada; ya que, 
además de sus aportes respecto a la reintegración de excombatientes al campo laboral, la contribución económica, la formación y capacitación; ayuda a crear condiciones reales para la construcción de una paz estable y duradera.

Como sustentan Rettberg et al. (2003), al referirse al papel de las empresas en procesos de conflicto y posconflicto:

La disposición del sector privado a apoyar la paz y asumir parte de sus costos ha sido determinante primero para precipitar un ambiente favorable a la negociación y, segundo, para generar las condiciones económicas propicias para la estabilidad del post-conflicto en esos países. Una agenda para el postconflicto debe preguntarse en qué radica el aporte (o los obstáculos) del sector privado a la construcción de paz, en qué condiciones el sector privado decide vincularse a los esfuerzos dirigidos a construir paz y qué formas puede adquirir la participación del sector privado en la construcción de paz en Colombia. (Rettberg et al., 2003, p. 25)

Si bien el aporte del sector privado comúnmente se asocia con apoyo económico y empleabilidad, éste aporte debe descansar sobre el respecto a la dignidad humana y los DD.HH en el campo laboral. En un escenario de posconflicto, donde la gobernanza, la institucionalidad y las garantías fundamentales, son débiles y proclives a reincidir en su vulnerabilidad, las empresas tienen la responsabilidad de garantizar los mínimos de justicia, reconocimiento y solidaridad en el espacio laboral, velando por la dignidad humana a sus stakeholders.

Las organizaciones deben propiciar espacios de encuentro, diálogo intercultural, respeto por las minorías y las diferencias, condiciones laborales dignas, libres de acoso laboral y exclusión (política, económica, por género, etnia, o por condición sexual o religiosa), conforme con los principios del Pacto Global (Universidad Externado de Colombia y Red Pacto Global Colombia, 2015):

- Trabajo forzado

- Discriminación laboral

- Trabajo infantil

- Libertad de asociación sindical

Hay una verdad sobreentendida que los empresarios conocen con suficiencia: "No existen las inversiones estables en sociedades que no lo son". Esta acepción lleva al cuestionamiento: ¿qué tipo de empresas son legítimas en un escenario de posconflicto en Colombia?

El papel del sector empresarial en anteriores procesos de paz como el de Belisario Betancourt (1982-1986), Virgilio Barco (1986-1990), César Gaviria (190-1994), Samper (1994-1998), Pastrana (1998-2002) y Uribe (2002-2006), no fue significativo; "la construcción de paz era menester estatal", donde el sector privado y la sociedad civil, "poco o nada tenían por aportar" (Tabla 1).

Tabla 1. Activismo empresarial en los procesos de paz en Colombia (1982-2006)

\begin{tabular}{|c|c|c|c|c|c|c|}
\hline \multirow[b]{2}{*}{ ACTIVISMO EMPRESARIAL } & \multicolumn{6}{|c|}{ PERIODO PRESIDENCIAL } \\
\hline & $\begin{array}{c}82-86 \\
\text { Betancur }\end{array}$ & $\begin{array}{l}86-90 \\
\text { Barco }\end{array}$ & $\begin{array}{c}90-94 \\
\text { Gaviria }\end{array}$ & $\begin{array}{c}\text { 94-98 } \\
\text { Samper }\end{array}$ & $\begin{array}{c}\text { 98-02 } \\
\text { Pastrana }\end{array}$ & $\begin{array}{l}\text { 02-06 } \\
\text { Uribe }\end{array}$ \\
\hline Declaraciones públicas & $\mathbf{x}$ & $\mathbf{x}$ & $\mathbf{x}$ & $\mathbf{x}$ & $\mathbf{x}$ & $\mathbf{x}$ \\
\hline Reuniones con negociadores oficiales o presidente & $\mathbf{x}$ & & $\mathbf{x}$ & $\mathbf{x}$ & $\mathbf{x}$ & \\
\hline Creación y participación en foros y mesas de trabajo & $\mathbf{x}$ & & & $\mathbf{x}$ & $\mathbf{x}$ & $\mathbf{x}$ \\
\hline contactos con actores armados & & $\mathbf{x}$ & & $\mathbf{x}$ & $\mathbf{x}$ & \\
\hline Participación activa en mesas oficiales de negaciación & & $\mathbf{x}$ & & $\mathbf{x}$ & $\mathbf{x}$ & \\
\hline Participación como veedores/verificadores de acuerdos de Paz & $\mathbf{x}$ & & & & & \\
\hline Creación de iniciativas de paz en el país & & & & & $\mathbf{x}$ & \\
\hline Pago de cargas fiscales & $\mathbf{x}$ & & $\mathbf{x}$ & & $\mathbf{x}$ & $\mathbf{x}$ \\
\hline Participación activa en políticas de reintegración de desmovilizados & & $\mathbf{x}$ & $\mathbf{x}$ & & & $\mathbf{x}$ \\
\hline
\end{tabular}

Fuente: Tomado de Aceros y Rettberg, 2013 
En los actuales diálogos de paz en La Habana, el sector empresarial tiene un rol protagónico en la construcción de paz, distinto al papel pasivo de anteriores procesos. El discurso de los DD.HH ha permeado campos sociales, empresariales y laborales, mediante la introducción de guías, estándares internacionales, políticas públicas con enfoque laboral, sistemas jurídicos, manuales y mecanismos de Responsabilidad Social Empresarial, y ha hecho que se involucren más empresas en la construcción de paz (Figura 4) (CCB y FIP, 2015).

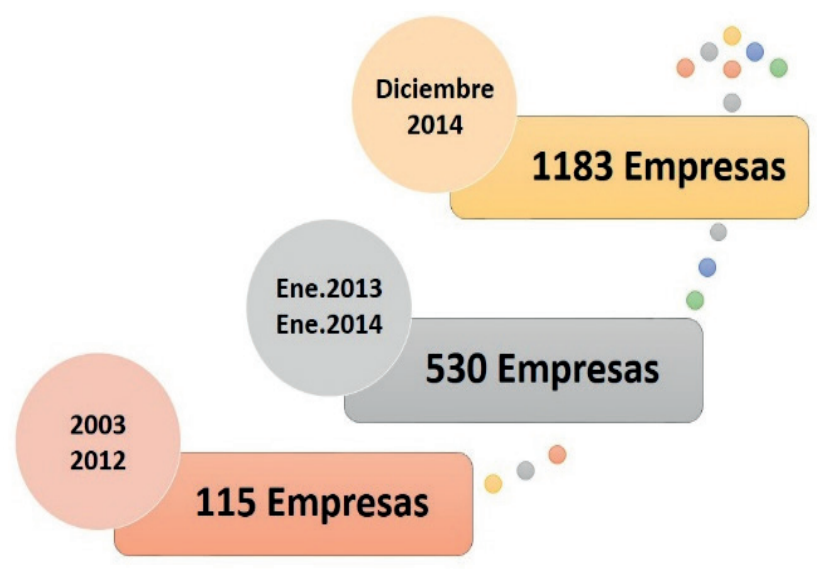

Figura 4. Empresas comprometidas en el proceso de paz Fuente: (CCB \& FIP, 2015) / Elaboración: Propia de los autores

Este compromiso se materializa conforme a experiencias nacionales e internacionales, a partir de capital político y económico, como:

- Apoyoy confianzaa las políticas gubernamentales.

- Facilitadores del acercamiento con grupos ilegales.

- Creación de empleo para excombatientes.

- Financiación de investigaciones sobreconflicto armado.
- Contribución a la reconstrucción del tejido social.

- Creación de centros de formación y capacitación para el trabajo.

- Atención a población vulnerable en razón del conflicto armado.

- Apoyo a las iniciativas de emprendimiento.

De acuerdo con Maurice Armitage, empresario secuestrado dos veces por las FARC y Alcalde electo de Santiago de Cali (2016-2019):
La iniciativa privada puede solucionar sin problema la incorporación laboral de excombatientes guerrilleros tras la firma de la paz. "El problema de los reinsertados no es grave, no entiendo por qué la gente lo ve así. Suponga que hay 10.000 guerrilleros, como dicen que hay, y que se reinsertan. En Colombia hay más de 10.000 empresas y con que cada una diera un empleo, resolveríamos el problema. (CCB y FIP, 2015, p. 22)

En los términos de Armitage, el compromiso de la empresa en la construcción de paz es un compromiso ético, una obligación, una oportunidad, de los empresarios para ser responsables socialmente en contextos complejos como el colombiano.

Con el ánimo de mitigar la vulneración de los Derechos Fundamentales dentro del contexto empresarial-laboral y orientar la participación de las organizaciones, públicas, privadas y del sector, en un futuro escenario de posconflicto, se plantean estándares, normativas y/o lineamientos, que promueven lo que la OIT ha denominado trabajo decente inclusivo; entendido este como condiciones de bienestar, y que contiene cuatro pilares: oportunidades laborales, protección de riesgos en el trabajo, diálogo social y protección social (Figura 5) 


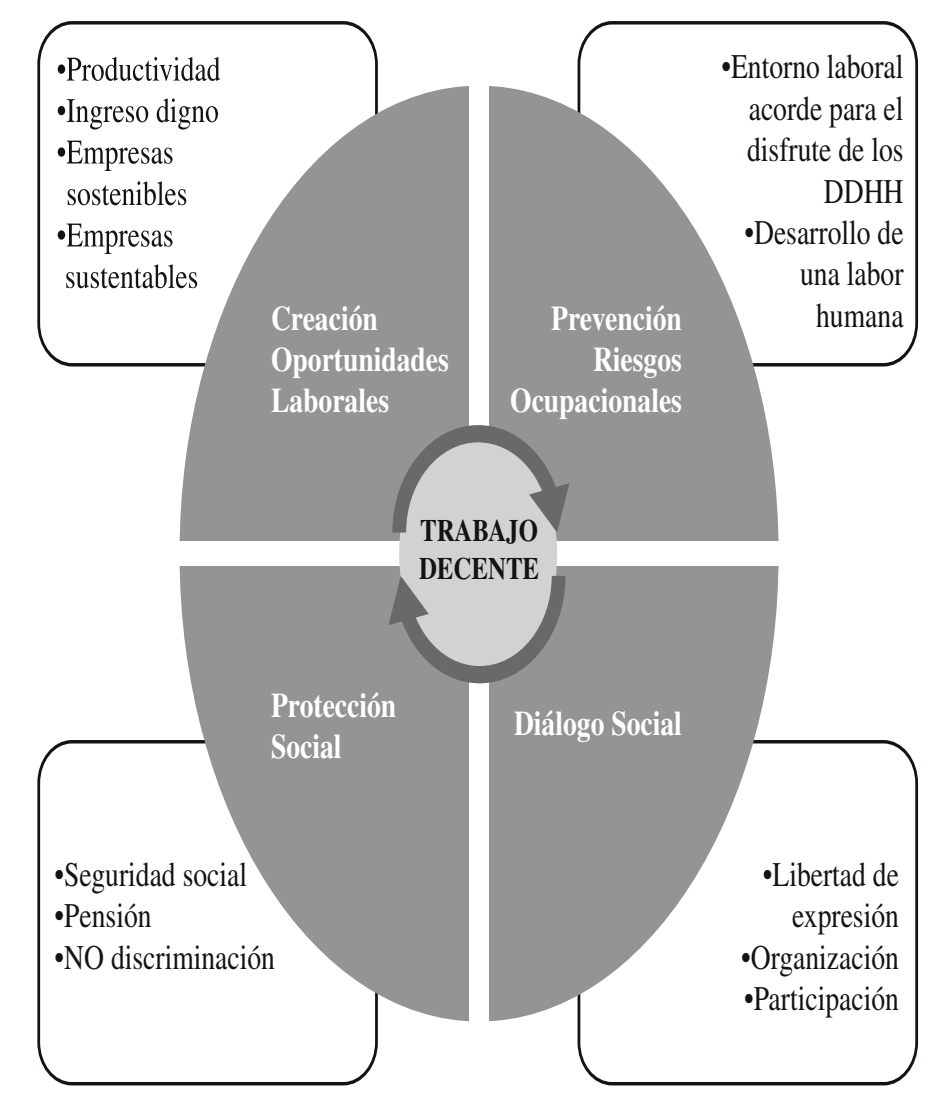

Figura 5. Pilares del trabajo decente

Fuente: (CCB y FIP, 2015) / Elaboración: propia de los autores

Estos cuatro pilares son, en términos de Cortina (2003), los referentes mínimos que toda persona desearía para laborar en condiciones de respeto, igualdad y justicia, por ende respetuosa de los DD.HH. Es decir, son pilares encaminados a propiciar el encuentro entre iguales desde una ética intercultural, a partir del diálogo y el reconocimiento del otro como interlocutor válido. Este sería un clima organizacional dentro de un escenario de posconflicto, donde, por diferente que parezca, es un "alguien" dotado de dignidad y por tanto con derechos que deben ser reconocidos.

Según la Organización para la Cooperación y el Desarrollo Económico - OCDE, existen cinco pilares que se deben considerar en zonas afectadas por el conflicto (2010) que quieren pasar al posconflicto: respeto por los DD-HH; procesos políticos y económicos participativos; fortalecimiento de instituciones públicas; fortalecimiento seguridad y justicia, y fortalecimiento de la sociedad civil. (Rettberg et al., 2003, p. 16)

Los análisis hasta acá realizados aportan a la discusión y comprensión de la ética de las empresas $\mathrm{u}$ organizaciones, en el sentido que, mediante la presentación y análisis de actuaciones o sucesos ocurridos como parte del conflicto en los que estas organizaciones se han visto involucradas, así como los aportes que se requieren de las organizaciones, públicas, privadas y del tercer sector, en un escenario de posconflicto o de construcción de paz, se sustenta el reconocimiento de la ética empresarial en el marco de los mínimos planteados por Cortina (1995; 2002; 2006) y Villafañe (2003). Esto permite identificar la ética de las organizaciones como el sustento de las decisiones y acciones, producto de la conjugación de principios morales y principios productivos de la organización. 
Se confirma la necesidad de que las empresas trasciendan el paradigma tradicional de maximización del beneficio, como lo sustenta Brenkert (2010), como un primer aporte a la construcción de paz. Adicionalmente, se formula la transformación del paradigma tradicional de Responsabilidad Social Empresarial/Corporativa como único aporte de las organizaciones en un escenario de posconflicto, ratificando la necesidad de que estas inicien un proceso de revisión y replanteamiento de sus decisiones y acciones, desde la concepción ampliada de la ética y conciban la responsabilidad social (RS), como una de sus dimensiones.

Se proponen las organizaciones, públicas, privadas y del sector, como principales dinamizadores de organización y reorganización social, en torno a la construcción de una paz estable y duradera, donde estas organizaciones sustenten, como primer aporte, la promoción y respeto de estándares, normativas y/o lineamientos de trabajo decente e inclusivo: oportunidades laborales, protección de riesgos en el trabajo, diálogo social y protección social.

\section{Conclusiones}

La empresa como actor protagónico en un escenario de posconflicto en Colombia debe empoderarse de la construcción de una paz, estable y duradera. Si bien su contribución económica y de inclusión laboral es su tarea primaria, estos aportes responden a un compromiso dentro de un modelo integral que implica prácticas empresariales responsables, transparentes y justas, en el marco de la protección de los derechos humanos, como condición de posibilidad del reconocimiento y el respeto al principio de dignidad, tanto personal como dentro de la empresa. La dignidad humana representa una de las mayores conquistas de la humanidad en aras de fomentar la ética de los derechos de las personas $\mathrm{y}$ es fundamental en sociedades en transición del conflicto a la arquitectura del posconflicto.

En el contexto colombiano, la ética empresarial se enfrenta a dos fenómenos contradictorios que la confirman como esencia de las organizaciones y de su relación con la sociedad, pero la desvirtúan como fundamento delimitante de su actuar (decisiones). Por un lado, está la proliferación de empresas que incursionan y promulgan desarrollar sus actividades en el marco de la ética empresarial y la Responsabilidad Social Corporativa -RSC, y que confirman la relevancia que la ética empresarial ha adquirido para las organizaciones; por el otro, están los continuos, y casi cotidianos, sucesos o eventos reprochables de organizaciones privadas, públicas y del tercer sector, que ponen en revisión la ética empresarial y principios de RSC, de estas organizaciones.

Por esto, es preciso promover en las organizaciones el valor de la ética empresarial en el marco de la protección de los derechos humanos, la equidad, la justicia y el respeto. Como lo establecen Cortina (1995; 2002; 2006) y Villafañe (2003): la ética de las organizaciones es el sustento de las decisiones y acciones, producto de la conjugación de principios morales y principios productivos de la organización.

De acuerdo con lo analizado, en un escenario de posconflicto en Colombia, las organizaciones, públicas, privadas y del tercer sector, deberán enmarcar sus decisiones en estándares mínimos que promuevan la inclusión social, reivindiquen los derechos humanos a partir de buenas prácticas organizacionales y promuevan los pilares propuestos por la OIT: oportunidades laborales, protección de riesgos en el trabajo, diálogo social $y$ protección social, reivindicando el trabajo decente e inclusivo, como principio garante para la construcción de una paz estable y duradera.

No obstante, es preciso ampliar el alcance de esta investigación, considerando los principios de medio ambiente y anticorrupción, propuestos por el Pacto Global, como elementos complementarios e imprescindibles de una ética empresarial integral para el posconflicto, logrando decisiones éticas por parte de las organizaciones y con acciones de responsabilidad social que tengan impactos significativos en los territorios. 


\section{Referencias bibliográficas}

Aceros, J. L. y Rettberg, A. (2013). La empresa de la paz. Negociaciones de paz y empresarios en Colombia (1982-2006). Bogotá D.C: Universidad de los Andes,

Alvarez, S. y Rettberg, A. (2008). Cuantificando los efectos económicos del conflicto: una exploración de los costos y los estudios sobre los costos del conflicto armado colombiano. Colombia Internacional, 67 (192), 14-37.

Asamblea General de las Naciones Unidas. (1948). Declaración universal de los derechos humanos. Naciones Unidas. Recuperado de http://www.un.org/ es/documents/udhr/index_print.shtml

BBC Mundo. (2004). Colombia: bananera paga extorsión. British Broadcasting Corporation. Recuperado de http://news.bbc.co.uk/hi/spanish/latin_america/ newsid_3705000/3705967.stm

Bello, M. (2003). El desplazamiento forzado en Colombia: acumulación de capital y exclusión social. Aportes Andinos, 7, 1-8. Recuperado de http://hdl. handle.net/10644/613

Brenkert, G. (2010). The Limits and Prospects of Business Ethics. Business Ethics Quarterly, 20(4), 703-709. http://doi.org/10.5840/beq201020444

Brito, M. (2007). Gobernanza empresarial: ética, responsabilidad social y rentabilidad en la "era posenrom." Revista Venezolana de Gerencia, 12 (38), 183-206.

Bunse, S. y Colburn, F. (2009). Chiquita en Colombia. Academia-Revista Latinoamericana de Administracion, 43, 174-181.

CCB y FIP. (2015). El sector empresarial y la construcción de paz: cómo apoyar iniciativas de empleabilidad de personas en proceso de reintegración - PPR desde el sector empresarial. Construcción de paz en Colombia. Recuperado de http://bibliotecadigital.ccb.org.co/bitstream/handle/11520/14038/13 reintegracion economica y empresas.pdf? sequence $=1 \&$ isAllowed $=\mathrm{y}$
Collier, P., Hoeffler, A. y Söderbom, M. (2008). Postconflict Risks. Journal of Peace Research, 45(4), 461-478. http://doi.org/10.1177/0022343308091356

Cortina, A. (1995). Ética empresarial y opinión pública. Claves de razón práctica, 56, 48-75.

Cortina, A. (2002). Educación en valores y responsabilidad cívica. Bogotá D.C.: El Búho.

Cortina, A. (2003). Construir confianza: ética de la empresa en la sociedad de la información y las comunicaciones. Recuperado de https://books.google.com/ books? $\mathrm{id}=\mathrm{oR} 0-\mathrm{HHe} 1 \mathrm{EVUC} \&$ pgis $=1$

Cortina, A. (2006). Ética del desarrollo: un camino hacia la paz. Revista Sistema, 192, 3-18. Recuperado de http://dialnet.unirioja.es/servlet/articulo? codigo=1 $958508 \&$ info $=$ resumen

Crespo, M. F. (2003). Lo ético de la ética empresarial. Revista Venezolana de Gerencia, 8(22), 307-322.

Fundación Ideas para la Paz y Embajada Británica en Bogotá. (2012). Libro blanco sobre empresas y derechos humanos en Colombia. Fundación ideas para la paz. Recuperado de http://datateca.unad.edu. co/contenidos/107038/Entorno_de_conocimiento/ Unidad_3/Tema_2/Libro_Blanco_Version_1.pdf

Gómez, H. C. (2015). Control territorial y resistencias: una lectura desde la seguridad humana. Medellín: Universidad de Antioquia.

González, J. I. (1987). Proyecto de hermano: visión creyente del hombre (Vol. 40). Bilbao: Sal Terrae.

Goodpaster, K. E. (1991). Business Ethics and Stakeholder Analysis. Business Ethics Quarterly, 1 (1), 53-73. http://doi.org/10.2307/3857592

Grasa, R. y Mateos, Ó. (2014). Guía para trabajar en la construcción de la paz: qué es y qué supone la construcción de la paz. Recuperado de file:///C:/Users/afochoa/Downloads/Guia Construccion Paz.pdf

Guáqueta, A. (2006). Operando en medio del conflicto: construcción de paz y algunas mejores prácticas de empresas colombianas (No. 2). Bogotá: Fundación Ideas para la Paz y International Alert. 
Hernández, A. (2006). La teoría ética de Amartya Sen. Bogotá: Siglo del Hombre Editores.

Idahosa, P. (2002). Business Ethics and Development in Conflict (Zones): the Case of Talisman Oil. Journal of Business Ethics, 39 (3), 227-246. http:// doi.org/10.1023/A:1016546308886

Idemudia, U. (2010). Rethinking the Role of Corporate Social Responsibility in the Nigerian Oil Conflict: the Limits of CSR. Journal of International Development, 22 (7), 833-845. http://doi.org/10.1002/jid

Idemudia, U. (2014). Corporate social responsibility and development in Africa: issues and possibilities. Geography Compass, 8(7), 421-435. http://doi. org/10.1177/097168589800400207

Izaguirre, I. y Aguiar, E. (1998). Violencia social y derechos humanos. Buenos Aires: Eudeba

Katsos, J. E. y Forrer, J. (2014). Business Practices and Peace in Post-conflict Zones: Lessons from Cyprus. Business Ethics: A European Review, 23(2), 154-168. http://doi.org/10.1111/beer.12044

Kolk, A. y Lenfant, F. (2013). Multinationals, CSR and Partnerships in Central African Conflict Countries. Corporate Social Responsibility and Environmental Management, 20 (1), 43-54. http://doi.org/10.1002/ csr.1277

Laborie Iglesias, M. A. (2010). La controvertida contribución de las empresas militares y de seguridad privadas (EMSP) a la resolución de conflictos. Cuadernos de Estrategia, 147, 77-138.

Llano, A. y Llano, C. (2004). Paradojas de la ética empresarial. Revista Empresa y Humanismo, 1, 69-89. Recuperado de https://core.ac.uk/download/ files/639/25070896.pdf

Miranda, C., Palou, J. C., Llorente, M. V., Rivas, A., Prieto, C. A. y Navarrete, C. M. (2012). Líderes empresariales hablan de la paz con las FARC. Fundacion Ideas para la Paz. Bogotá D.C. Recuperado de http:// humanas.org.co/archivos/ideasparalapazlideresempresariales.pdf
Molina, N. F. S. (2015). Ética de las organizaciones. Reflexión del saber. Medellin: Universidad Pontificia Bolivariana.

Muñoz-Martín, J. (2013). Ética empresarial, responsabilidad social corporativa (RSC) y creación de valor compartido (CVC). Journal Globalization, Competitiveness and Governability, 7 (3), 76-88. http://doi.org/10.3232/GCG.2013.V7.N3.05

Naciones Unidas. (2015). Informe del alto comisionados de las naciones unidas sobre la situación de los derechos humanos en Colombia. Recuperado de http://www2.ohchr.org/spanish/bodies/hrcouncil/ docs/gaA.RES.60.1_Sp.pdf

Rettberg, A. (2003). Administrando la adversidad: respuestas empresariales al conflicto Colombiano. Colombia Internacional, 55, 37-54.

Rettberg, A. (2007). The Private Sector and Peace in El Salvador, Guatemala and Colombia. Journal of Latin American Studies, 39 (3), 463-494. http://doi. org/10.1177/1468018105053677

Rettberg, A. (2008). Explorando el dividendo de la paz: impactos del conflicto armado en el sector privado colombiano (Primera, Vol. 3). Uniandes. Recuperado de http://faciso.uniandes.edu.co/cesol nhttp://ediciones.uniandes.edu.co

Rettberg, A. (2010). Colombia 2009, progreso e incertidumbre. Revista de Ciencia Política, 30 (2), 249-273.

Rettberg, A., Camacho, A., Chaux, E., García, A., Itturralde, M., Sánchez, F. y Wills, L. (2003). Preparar el futuro: conflicto y post-conflicto en Colombia. Bogotá D.C.: Alfaomega.

Rojas-Aravena, F. y Goucha, M. (2001). Seguridad humana, prevención de conflictos y paz en America Latina y el Caribe. Santiago-Chile: Unesco y Flacso

Rubio, R., Ramírez, A. C., Fandiño, S., Suárez, G. y Mesías, L. (2004). La academia y el sector rural 2. Bogotá D.C. : Universidad Nacional de Colombia. 
Somavía, J. (2014). El trabajo decente: una lucha por la dignidad humana (1st ed.). Santiago: OIT. Recuperado de http://www.ilo.org/santiago/publicaciones/WCMS_380833/lang--es/index.htm

Taylor, C. (1993). El multiculturalismo y la "política del reconocimiento". México: Fondo de Cultura Económica.

Tindall, S. (2014). The Modern Perils of Business Ethics. The Business, 85 (1), 22-24.

Tsalikis, J., Seaton, B. y Shepherd, P. L. (2014). Business Ethics Index: Latin America. Journal of Business Ethics, 119, 209-218. http://doi.org/10.1007/ s10551-012-1587-9

United Nations Global Compact. (2010). Lineamientos sobre responsabilidad empresarial en áreas de alto riesgo y afectadas por conflictos: recursos para empresas inversionistas. New York.
Universidad Externado de Colombia y Red Pacto Global Colombia. (2015). Casos para la construcción de un mundo mejor: el compromiso empresarial para la arquitectura post 2015. Bogotá D.C. Recuperado de http://www.pactoglobal-colombia.org/images/pdf/ Casos_Pacto_global_final.pdf

Vargas-Valdez, R. E. (2010). Cumplimiento institucional en la defensa de los derechos humanos a partir del acuerdo de paz. San Salvador: Universidad Tecnológica.

Villafañe, J. J. (2003). Influencia de la comunicación en la reputación corporativa. En A. Cortina. (Ed.), Construir confianza: ética de la empresa en la sociedad de la información y las comunicaciones (pp. 169-184). Madrid: Trotta. 